\title{
RECUERDOS DE UN TIMONEL: MICHEL MAFFIOTE Y LA RENDICIÓN DE LA ESCUADRA DE ROSILY EN LA BATALLA DE LA POZA DE SANTA ISABEL (1808)
}

\author{
Lourdes Márquez Carmona \\ Licenciada en Geografía e Historia
}

\section{RESUMEN}

Se analiza la rendición de la escuadra del vicealmirante Rosily durante el desarrollo de la Batalla de la Poza de Santa Isabel, primer conflicto armado de la marina de España contra las tropas invasoras de Napoleón Bonaparte, que tuvo lugar en la Bahía de Cádiz en junio de 1808. Todo ello, aportando una inédita visión a través de las memorias de Michel Maffiotte, timonel del navío Indomptable, hundido en 1805 después de la Batalla de Trafalgar, que luchó junto a Rosily, jefe de la armada francesa, y que tras el combate fue capturado y deportado como prisionero de guerra a las Islas Canarias.

Palabras claves: Cádiz; España - 1808-1814 (Guerra de la Independencia); Historia Naval; Maffiotte, Michel; Poza de Santa Isabel, Batalla de, 1808; Rosily, François-Etienne de.

\section{ABTRACT}

In this paper we analyze the surrender of Viceadmiral Rosily's squadron in the battle of the 'poza' (submarine depression) of Santa Isabel, the first armed conflict between the Spanish navy and Napoleon's invading troops, which took place in the Bay of Cadiz in June 1808. We provide an original perspective from the memoirs of Michel Maffiotte, a former helmsman of the Indomptable (sunken at the Battle of Trafalgar, 1805), who later rejoined chied commander Rosily, and was eventually captured and deported as a prisoner of war to the Canary Isles.

Key words: Cádiz; Spain - 1808-1814 (Independencia War) ; Naval History; Maffiotte, Michel; Poza de Santa Isabel, Battle of, 1808; Rosily, François-Etienne de.

Entre el 9 y el 14 de junio de 1808 tuvo lugar la Batalla de la Poza de Santa Isabel, el último acontecimiento bélico en el que participaron los restos de la flota francesa que luchó en el Combate Naval de Trafalgar, la trascendental batalla que enfrentó la escuadra hispano-francesa con la flota inglesa de Lord Nelson, el 21 de octubre de 1805, en aguas del litoral de Cádiz. 
El destino de dicha escuadra estaba predestinado pues jamás regresaría ninguno de sus barcos a fondear en puerto francés, ya que gran parte de la flota se hundió a consecuencia del fuerte temporal del suroeste que se desató los días siguientes al combate, y los navíos de línea supervivientes, no abandonarían jamás la Bahía de Cádiz arbolando pabellón francés.

Tras múltiples vicisitudes, cuyo interés va más allá del objetivo de este trabajo y del cual existe una amplia bibliografía en la historiografía naval francesa, española e inglesa, sólo unos pocos barcos del total de 33 navíos que componían la escuadra aliada consiguieron arribar a la Bahía de Cádiz, y de ellos sólo 5 navíos de línea de nacionalidad francesa: Herós, de 84 cañones, Algeciras, de 86 cañones, Plutón y Argonaute, de 74 y el de mayor porte, el Neptune, con 92 cañones y la fragata de 42 cañones denominada Cornelia.

Esa es la reducida escuadra de la que el vicealmirante Rosily tuvo que asumir el mando, relevando al gran vencido de Trafalgar, el almirante Villeneuve, derrotado por parte de los ingleses y caído en desgracia ante el emperador Napoleón Bonaparte.

Cuando François-Etienne de Rosily-Mesros [Fig.1], nacido en 1748 y fallecido en 1832, llegó a Cádiz en octubre de 1805 era ya un experimentado marino ${ }^{1}$, con una importante carrera militar realizada en la marina francesa. Al abandonar su país para obedecer las órdenes de Napoleón de asumir el mando de la escuadra combinada, desempeñaba el cargo de director, desde el año 1795, del Dépôt de la Marine Française. Este cuerpo era el encargado de la elaboración y gestión de la cartografía náutica, necesaria para las navegaciones oceánicas de las unidades navales de Francia.

A su llegada a Cádiz Rosily debió asumir el mando de una maltrecha flota, tanto por el estado material de los buques, como por el aspecto físico y moral de las tripulaciones. Sin duda, el desánimo reinaría en la mente de unos hombres que debieron padecer tantas calamidades, desde que Villeneuve adoptó la equivocada decisión el 19 de octubre de 1805, a pesar de la oposición de los mandos españoles, de dar la orden de salir del puerto gaditano para dar encuentro a la armada inglesa.

Sin embargo, antes de entrar a describir los sucesos que acontecieron a mediados de junio de 1808 en el sur de la Península Ibérica, es necesario realizar un pequeño encuadre histórico de la situación que se estaba viviendo en España en general y en Cádiz en particular.

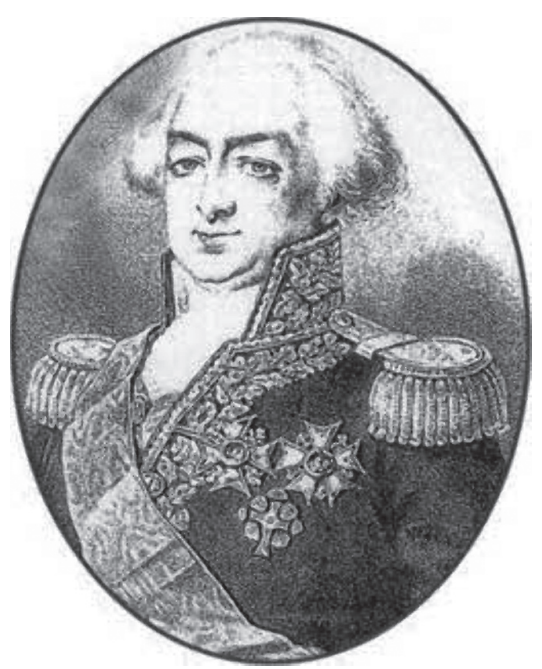

Fig. 1: Vicealmirante François-Etienne de Rosily.

\footnotetext{
1 HENNEQUIN, Joseph François Gabriel : Biographie maritime: ou, Notices historiques sur la vie et les campagnes des marins célèbres français et étrangers, [s.1], Regnault, 1837, p.778.
} 
Napoleón Bonaparte, emperador de Francia y supuesto aliado del rey español Carlos IV, seguía secretamente la estrategia de hacerse con el gobierno de España y con el poder naval de su armada, un elemento fundamental en sus planes para obtener el control de los mares y permitir su gran objetivo: la invasión de Inglaterra. La derrota y pérdida de tantos efectivos navales a consecuencia de la Batalla de Trafalgar supuso un gran revés para sus ambiciones, imposibilitando la ansiada invasión y el abandono de las operaciones marítimas. Ello supuso la focalización de los esfuerzos de Napoleón en alcanzar el dominio de Europa, incluida España.

La abdicación de Carlos IV a favor de su hijo Fernando VII en marzo de 1808 tras el Motín de Aranjuez; la salida de la familia real hacia Bayona, donde Carlos IV, que había recuperado el trono, abdica de nuevo esta vez a favor de Napoleón, y los excesos cometidos por las tropas imperiales francesas en tierras españolas, provocaron la indignación popular en todo el país. El traslado forzoso de Madrid de los infantes Francisco Pablo y María Luisa, ordenado por el mariscal Murat, fue el detonante que provocó el conocido levantamiento del "Dos de Mayo" en Madrid y el posterior alzamiento general de la nación contra José Bonaparte I, hermano de Napoleón, recién nombrado rey de España. Ante tales acontecimientos, todo el territorio español se alzaría paulatinamente en contra del invasor, iniciándose la Guerra de la Independencia.

A partir de este punto se sucedieron una serie de hechos en diversos lugares del territorio nacional: la Batalla de Bailén; los sitios de Zaragoza y Gerona; la creación de mecanismos de gobierno a través de la Junta Suprema Central y Juntas locales; la organización de una fuerza militar mediante la creación de ejércitos regionales y diversos cuerpos de voluntarios; la rendición de la armada francesa de Rosily; la presencia del ejercito aliado inglés en la Península Ibérica; la implantación de la táctica de guerrillas; batallas de distinto signo (Bruch, Tudela, Somosierra, Uclés, Elviña, Talavera, Almonacid, Ocaña, Arapiles, Vitoria, San Marcial); el repliegue del gobierno provisional a Cádiz; la defensa de la plaza gaditana, último reducto sin dominar; las últimas contraofensivas; la salida de España del rey José y la derrota final de Napoleón en España².

Mientras se sucedían los primeros hechos de la Guerra de la Independencia, en la Bahía de Cádiz seguía fondeada la escuadra de Rosily. El almirante inglés Purvis, a las órdenes directas de Collingwood -que permaneció al mando de la escuadra inglesa después de la muerte del almirante Nelson en Trafalgar-, se mantenía frente a la ciudad impidiendo la entrada o salida de cualquier embarcación de la rada, bloqueando la pequeña armada gala por un período de tres años, desde 1805 a 1808 .

La situación se adivinaba complicada, pero el vicealmirante francés, por orden imperial, debía permanecer en Cádiz para apoyar a las tropas imperiales que marchaban en dirección sur³. Al mismo tiempo, Napoleón ordenó el traslado a esta urbe del general Francisco Solano, Marqués del Socorro y Capitán General de Andalucía , por considerarlo peligroso para sus planes ${ }^{4}$, dado que suponía que la presencia de la escuadra francesa en la Bahía le disuadiría de un intento de ir contra los intereses de Francia.

La noticia del alzamiento del "Dos de Mayo" llegó también, como era de esperar, a Cádiz. La población se preguntaba el motivo de no intentar rendir los navíos enemigos anclados en la Bahía. Solano, sin apenas infraestructuras para atacarla y mientras organizaba la táctica para rendirla, fue tachado de afrancesado e injustamente asesinado por el exaltado populacho ${ }^{5}$ y como así lo corrobora Maffiotte en su diario [Fig. 2]:

\section{... Dimanche 29 mai 1808 on a assassiné le gouverneur de Cadix. ${ }^{6}$. [Fig. 3]}

\footnotetext{
2 FERNÁNDO DE BORDEJE Y MORENCOS, F. : Crónica de la marina española en el siglo XIX, 1808-1868 (Tomo I), Madrid: Ministerio de Marina, 1999, p. 47.

FERNÁNDEZ DURO, Cesáreo: Armada española: desde la unión de los reinos de Castilla y de Aragón, Madrid: Museo Naval, 1972-1973, 9 v. Tomo IX, p. 12.

4 CASTRO, Adolfo: Historia de Cádiz y su provincia: desde los remotos tiempos hasta 1814. Cádiz: Imprenta de la Revista Médica, 1858, p. 574.

5 Ibidem, p. 590.

6 Trad:.. Domingo 29 de mayo de 1808 han asesinado al Gobernador de Cádiz....
} 


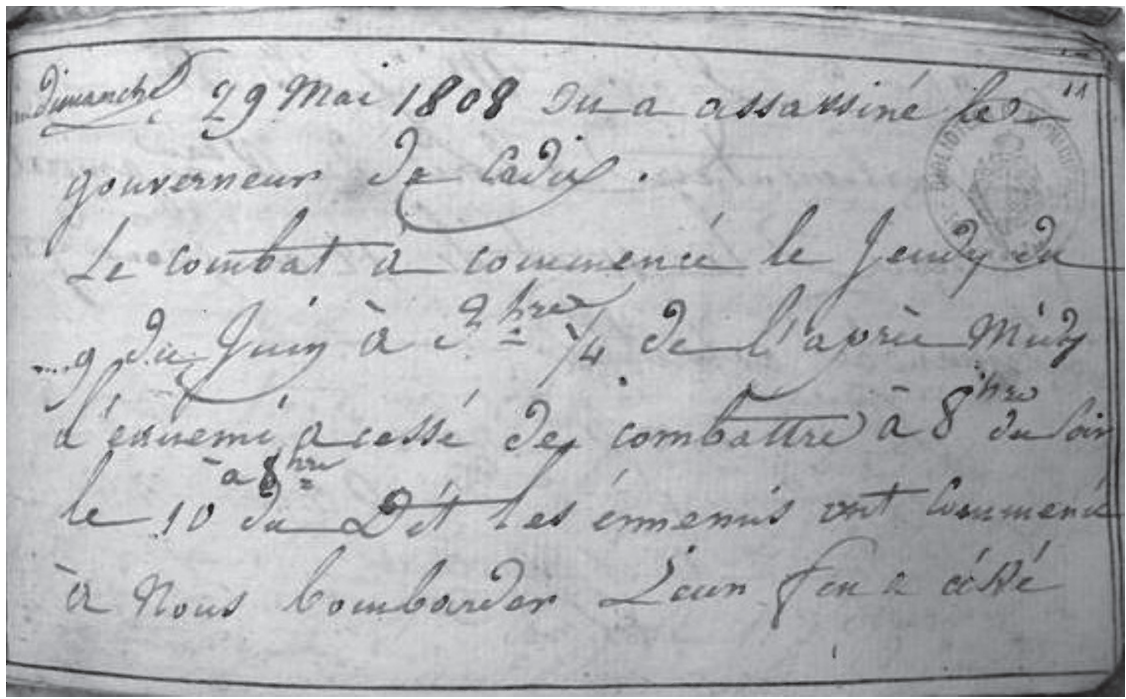

Fig. 2: Memorias de Michel Maffiotte. Biblioteca Pública de Santa Cruz de Tenerife.

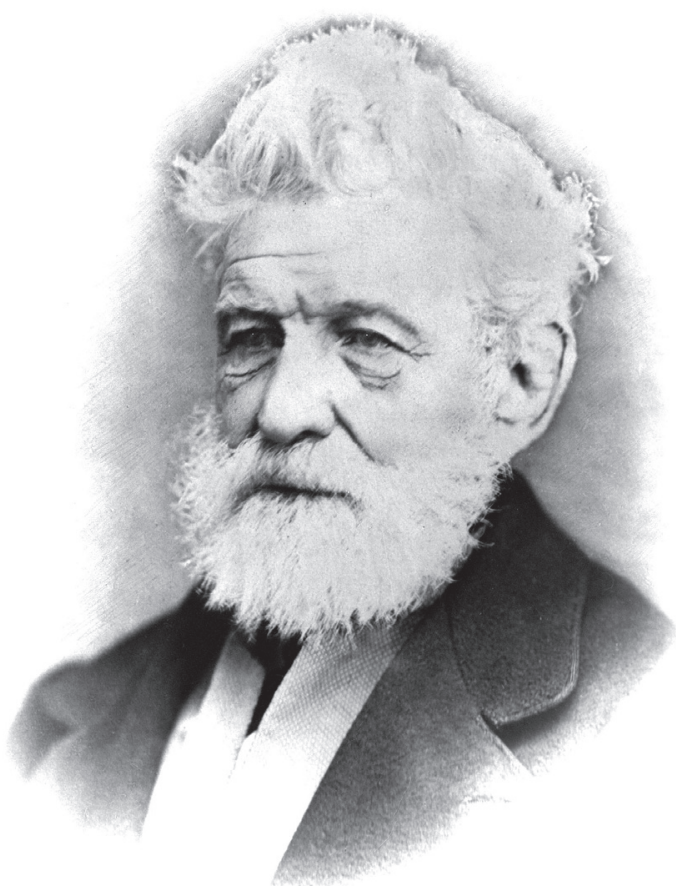

Fig. 3: Michel Maffiotte. 
La presencia francesa en La Bahía se dilataba ya demasiado en el tiempo. Ver sus barcos fondeados en la Bahía era ya habitual para los habitantes de Cádiz, San Fernando, Puerto Real y El Puerto de Santa María. Esos mismos habitantes tres años antes habían ayudado en las labores de auxilio de los supervivientes, españoles, franceses e ingleses, que llegaron a las costas del litoral de Huelva y Cádiz, tras el sangriento combate de Trafalgar y el fuerte temporal del suroeste que llevó a pique 15 navíos de línea de la Escuadra Combinada? .

Muchos de esos náufragos fueron protagonistas anónimos de dicho acontecimiento histórico. Uno de ellos, Michel Maffiotte dio cuenta a la Historia de esta tragedia ${ }^{8}$. Timonel del navio Indomptable, vio como perecieron muchos de los tripulantes del Bucentaure, buque insignia francés y de su propio barco. El joven Maffiotte consiguió a duras penas agarrado a una madera de su navío, luchando contra el fuerte oleaje, llegar a nado hasta las cercanías del Castillo de Santa Catalina de El Puerto de Santa María (Cádiz). Allí fue auxiliado por los soldados del Regimiento de Zaragoza que hacían guardia en la costa, incorporándose posteriormente una vez repuesto, a la tripulación del Neptune navío de línea francés.

Su deseo por preservar para el futuro sus vivencias fue más allá de la Batalla de Trafalgar, dando testimonio, con su particular e inédita visión, de la rendición de la Escuadra de Rosily tres años después de su llegada al sur de España.

Tras el duro combate de Trafalgar, sus días transcurrieron fondeado en un navío que se mantenía al ancla en la bahía gaditana. Esta larga estancia de los barcos franceses fue aprovechada por Rosily para confeccionar una detallada carta náutica ${ }^{9}$ de la zona, según los más avanzados métodos científicos de la época, permitiendo la ejecución de esta labor la formación que poseía como hidrógrafo.

Los amplios conocimientos que tenía Rosily de la Bahía de Cádiz resultaron bien patentes en dicha carta náutica, publicada en el año 1807. En ella quedaron señalizados y clasificados perfectamente todos los bancos que ofrecían dificultades para la navegación; las abundantes cotas batimétricas que indicaban la profundidad del fondo en la unidad de medida de pies francés; el tipo de fondo (arena, roca, fango, concha); las fortificaciones; los puntos de aguada; el Arsenal de La Carraca y hasta incluso la plaza de toros de El Puerto de Santa María, etc. Todo un ejercicio de plasmación en una representación gráfica de los enclaves más importantes, sin lugar a dudas, para facilitar el control militar por parte de Napoleón de tan estratégico lugar del sur de España.

Por tanto, cuando el vicealmirante francés dio órdenes el 6 de junio de $1808^{10}$ a su escuadra de separarse de la escuadra española con la que mantenía una formación intercalada ${ }^{11}$, y cambiar de fondeadero dentro de la Bahía de Cádiz aprovechando una gran marea, sabía perfectamente donde tenía que echar anclas, como así lo demuestra el siguiente párrafo de la leyenda de dicha carta náutica:

...On a consideré les parties du fond de la mer sur lesquelles il reste plus de 24 Pieds d'eau comme practicables en tout tems méme pour les Vaisseaux de Ligne ${ }^{12} \ldots$

De este acontecimiento de la historia marítima de España contamos en esta ocasión con un testimonio de gran relevancia: Maffiotte, nuestro cronista particular, relata la rendición de la escuadra de Rosily en unas inéditas memorias ${ }^{13}$, tituladas "Mal designio. Memorias de Michel Maffiotte. El armero Maffiotte" que se conservan en la Biblioteca Pública de Santa Cruz de Tenerife ${ }^{14}$, escritas en francés y de la cual hemos realizado la traducción que facilitamos en los párrafos siguientes.

\footnotetext{
MÁRQUEZ CARMONA, Lourdes: Trafalgar y el pescador de náufragos, [Cádiz], Publicaciones del Sur 2005, p. 67.

Plan Hidrographique de la Baie de Cádiz levé en 1807 sous la direction de viceamiral Rosily ... Publié par ordre de son Excellance le Comte Decrès. au Dêpot Général de la Marine. Instituto de Cartografía de Andalucía. Sig: Joly (Colección privada) núm 32 ICA1988011183

10 HENNEQUIN, Joseph François Gabriel : Biographie maritime...op. cit., p.777.

11 BARBUDO DUARTE, Enrique: Apresamiento de la escuadra francesa del Almirante Rosily en la Bahía de Cádiz, el 14 de junio de 1808, Cádiz: Colección Fragata, 1987, p.11.

12 Trad:..Se ha considerado las partes del fondo de la mar sobre las cuales queda más de 24 pies de agua como practicables en todas las condiciones Incluso para los Navíos de Línea...

13 Agradecemos a César Rodríguez Maffiotte, tataranieto de Michel, la amabilidad con que nos facilitó dichas memorias.

14 Signatura MS 103.
} 
Michel Barthelemy Etienne Maffiotte nació el 11 de diciembre de 1786 en Sette (Francia). En 1801 fue enviado por sus padres, a la edad de 14 años, a la Escuela de Navegación de Tolón. Transcurridos tres años de estudio fue reclamado el 14 de julio de 1804, mediante una orden de movilización del emperador Napoleón, para embarcar en el navío Indomptable, anclado en el puerto de Tolón; lo que efectuaría 8 días más tarde, sin saber que jamás regresaría a su patria. Después de viajar hacia América con la Escuadra Combinada, de asistir a su regresó a España al combate de Finisterre (julio de 1805), el guardiamarina Maffiotte fue testigo, no sólo de los horrores del combate de Trafalgar (octubre de 1805), sino de la lucha que tuvieron que mantener contra el temporal las tripulaciones de los barcos supervivientes al combate.

Tras sobrevivir al naufragio de su navío ${ }^{15}$, en el que perecieron unos 900 franceses, cerca de la costa de El Puerto de Santa María (Cádiz), el timonel del Indomptable fue reembarcado en el navío francés Neptune. Su destino permanecería así unido al de su almirante Rosily y al resto de los marinos franceses.

En su diario anotó en francés, aunque sólo aportamos, como dijimos con anterioridad, la versión que hemos traducido:

Tomado para el Servicio el 14 de Julio de 1804. Embarcado a bordo del navío Indomptable el 22 del dicho. Partí de Tolón el 30 de Marzo 1805. Fondeé frente a Cádiz el 11 de Abril y zarpé la misma noche. Llegue a Port Royal el 14 de Mayo. Partí el 5 de Junio, alcancé el convoy el 7 del dicho. Combatí el 22 Julio, llegué a Vigo el 24 y partí el 31 del dicho. Llegué a La Coruña el 2 de agosto. Salí el 10 y fondeé en la bahía de Betanzos el 12 de Agosto. Fondeé en Cádiz el 20 del dicho. Salí de Cádiz el 20 de octubre. Combatí el 21 y fondeé en las afueras de la misma en el mismo día. Naufragué el 25 Octubre. Embarqué a bordo del N. El Neptune el 29 del dicho, pasé a la Timonería el 15 Noviembre.

..El $1^{\circ}$ Septiembre 1806 pasé a la cofa de mesana. El 9 Junio 1808 estando fondeado en el fondo de la bahía de Cádiz los españoles nos han bombardeado y han continuado hasta el 10 por la tarde. El 11 se parlamentó, la mañana y tarde, nada en la jornada. El 14 vino un parlamentario A bordo del $b$. Insignia y nuestro pabellón fue arriado a las 10 1/2 de la mañana. Desembarcado y conducido a prisión en el Arenal ${ }^{16}$ el mismo día....

Con respecto a los hombres y naves de la escuadra francesa hay que decir que Rosily contaba con un total de 3.676 hombres de tripulación y 6 embarcaciones ( 5 navíos de línea y 1 fragata), y un total de 398 cañones de capacidad artillera. Todos los navíos de línea tenían en común el ser bastante nuevos, con pocos años de haber salido de los arsenales franceses, y el ser levantados según el plan de construcción naval de Jacques Nöel Sané.

La dotación de la escuadra española era de 4.219 hombres y 6 embarcaciones, de ellas 5 navíos de línea: Terrible (74 c.), Montañés (74 c.), San Justo (74 c.), San Fulgencio (64 c.), San Leandro (64c.), el buque insignia de 112 cañones Príncipe de Asturias y la fragata Flora. Lo que sumaba un total de 496 cañones, bajo las órdenes del general Juan José Ruiz de Apodaca, excombatiente de Trafalgar.

Las diferencias entre las 2 escuadras era notoria, mientras que los navíos franceses se hallaban perfectamente pertrechados de víveres y municiones, los barcos españoles padecían todo tipo de carestías (escasez de alimentos, uniformes e impago de salarios entre la marinería y la oficialidad) ${ }^{17}$. De estas faltas, incluso de pólvora, elemento fundamental para emprender un ataque, era perfectamente consciente Francisco Solano, gobernador de Cádiz y capitán general de Andalucía. Por ello se negó a emprender el ataque de la escuadra, motivo por el cual fue injustamente asesinado por el populacho de Cádiz, como dijimos anteriormente.

\footnotetext{
MÁRQUEZ CARMONA, Lourdes: Trafalgar y el pescador de náufragos...op. cit., p.83.

Debe tratarse de una errata y referirse realmente al Arsenal de La Carraca, situado en San Fernando (Cádiz).

FERNÁNDEZ DURO, Cesáreo: Armada española: desde la unión...op. cit., p. 11.
} 
Su sustituto en el cargo, el general Tomás de Morla, jerezano de nacimiento y artillero de formación, evidentemente no se negó a las peticiones de rendir los navíos de Rosily ante la presión popular y visto el cruel final de su antecesor. Ante los graves disturbios producidos en Cádiz se vio incluso obligado el 30 de Mayo a efectuar una proclama al pueblo para calmar los exaltados ánimos:

Pueblo español, leales compatriotas, la voz de la razón me ha dictado estas reflexiones, y como Jefe os digo ahora, que os doy mi palabra de que los franceses muden el pabellón, o a lo menos no coloquen los suyos; pues cualquiera otra providencia acarrearía mil desgracias a nosotros mismos: no intentéis nada, pues destruiríais mi plan: ya tengo tomadas mis medidas y dentro de veinticuatro horas habéis de ver los efectos favorables que todos deseamos. Cádiz, 30 de mayo de 1808.- Morla $^{18}$

Se inician de este modo una serie de preparativos para rendir las embarcaciones francesas, pero primeramente era necesario asegurar una alianza con Inglaterra. Por lo que el general Apodaca negocia la paz con el almirante inglés Collingwood que se mantenía con sus barcos bloqueando Cádiz. Esta misión le fue encomendada, sin lugar a duda por el dominio de la lengua inglesa, al oficial de la armada española de origen irlandés Enrique Macdonnel ${ }^{19}$, comandante del navío Rayo naufragado los días siguientes al Combate de Trafalgar, en la antigua costa de Castilla, actual Arenas Gordas (Huelva), entre las Torres Vigías de Zalabar y Carboneros ${ }^{20}$.

Una vez asegurada la alianza con la escuadra inglesa y obtenido en préstamo de sus nuevos aliados 400 kilos de pólvora ${ }^{21}$, se preparó un plan de ataque para vencer a la flota francesa. Toda la planificación del mismo quedó al mando del Jefe del Arsenal de La Carraca, teniente general José Joaquín Moreno; del Gobernador de Cádiz y capitán general de Andalucía Tomás de Morla; del Jefe de la escuadra española, el general Ruiz de Apodaca y del Comandante del Cuerpo de Brigadas del Departamento de Cádiz, Diego de Alvear y Ponce de León ${ }^{22}$.

Estos mandos determinaron que las operaciones contra el enemigo debían consistir en separar las dos escuadras, que se encontraban dispuestos en formación de alternancia; impedir su salida de la Bahía de Cádiz; obstaculizar la navegación hacia el caño de la Carraca y movilizar todas las fuerzas navales disponibles.

El 30 de mayo, solicitando permiso a Rosily, la escuadra española con la excusa de ser el día de la jura de Fernando VII como Rey de España, se separó de la escuadra francesa y fondeó frente del Corral $^{23}$, entre la actual Punta de San Felipe y el castillo de San Lorenzo de Puntal o Puntales (Cádiz). Mientras, el vicealmirante Rosily era ya consciente de los preparativos de Napoleón de invadir España. Decrès, ministro de marina de Francia, le había dado órdenes de esperar al ejército de Dupont que bajaba hacia el sur por tierra para rendir la plaza de $\mathrm{Cádiz}^{24}$. Por lo que cuando el vicealmirante francés observó la maniobra de la escuadra española, junto con las operaciones de refuerzo que se hacían en el fuerte de Puntales y otras fortificaciones decide dirigirse hacia al saco interno de la Bahía, concretamente hacia la Poza de Santa Isabel, situada en el canal navegable que da acceso al Arsenal de La Carraca. Era la única opción que le quedaba al tener bloqueada la boca de la bahía por las escuadras española e inglesa.

Rosily sabía, como dijimos anteriormente, donde existía calado suficiente en el interior de la rada para fondear sus navíos de línea, como así marcaba en la carta náutica que realizó. Además, con este movimiento amenazaba con sus cañones al arsenal situado en la Real Isla de León o San Fernando.

\footnotetext{
18 PÉREZ DE SEVILLA Y AYALA, Vicente: La artillería española en el sitio de Cádiz, Cádiz: Instituto de Estudios Gaditanos, Diputación Provincial, 1978, p. 221.

9 FERNÁNDEZ DURO, Cesáreo: Armada española: desde la unión...op. cit., p 12

MÁRQUEZ CARMONA, Lourdes: Trafalgar y el pescador de náufragos...op. Cit., p.128.

PÉREZ DE SEVILLA Y AYALA, Vicente: La artillería española. ...op. cit., p. 220.

2 Marino que perdió a su esposa y 9 hijos durante el ataque de una escuadra inglesa que provocó la voladura de la Fragata Mercedes, en el Combate del Cabo de Santa María el 5 de octubre de 1804

23 CLAVIJO CLAVIJO, Salvador: La ciudad de San Fernando, historia y espíritu, San Fernando, Ayuntamiento, 1960 , p. 378.

${ }^{24}$ THIERS, Adolphe: Histoire du Consultat et de l'Empire: faisant suite à l'Histoire de la Révolution française, Paris, J.P. Meline, 1850. Tome 9. Livre 31. p. 2.
} 
De este modo se produjo el movimiento de la escuadra gala el día 6 de junio hacia la zona de fondeo de la Poza de Santa Isabel.

Mientras, la situación en tierra era la de disponer una serie de baterías de costa para atacar. De modo que brigadas de obreros tanto militares como civiles trabajaron sin cesar para montar una serie de baterías costeras, después de que Morla tomara la decisión de no arriesgar los navíos españoles, ya que el Príncipe de Asturias era el único que estaba en condiciones reales de luchar contra el enemigo.

Los españoles dispusieron así una corona de fuego alrededor de la escuadra fondeada en el saco interno de la Bahía de Cádiz [Fig. 4]. Se reforzaron los fuertes de San Luis y Puntales, se establecieron baterías provisionales en Puerto Real: en el canal norte del Trocadero y en el molino de Guerra y también en San Fernando: Baterías de los Dolores (Puente de Ureña), Casería de Osio y Lazareto, San Carlos y Arsenal de La Carraca. No obstante, la amenaza de Rosily al Arsenal de la Carraca era evidente, por lo que para cortarle el paso era necesario efectuar el cerramiento del canal de La Carraca. Para ello hundieron el navío Miño y la urca Librada en las proximidades de la Punta de la Clica, operaciones dirigidas por los ingenieros de marina al mando del general Rafael Clavijo ${ }^{25}$

Otra de las medidas dispuestas fue cerrar el saco interno de la bahía, para lo cual los españoles dispusieron una cadena flotante desde el Fuerte de San Luis en dirección suroeste, con el objetivo de cortar la posible salida de Rosily.

Asimismo, por el doble motivo de no arriesgar la escuadra española y la dificultad de maniobra para los navíos por el sitio tan angosto en que se hallaba la escuadra francesa, se decidió efectuar el ataque con el cuerpo de fuerzas sutiles formados por lanchas cañoneras ${ }^{26} \mathrm{y}$ bombarderas del Arsenal de La Carraca y del Apostadero de Cádiz, provista cada una de 60 tiros de munición. Se eligió como lugar de fondeo las cercanías del Fuerte de San Luis en el Trocadero ${ }^{27}$.

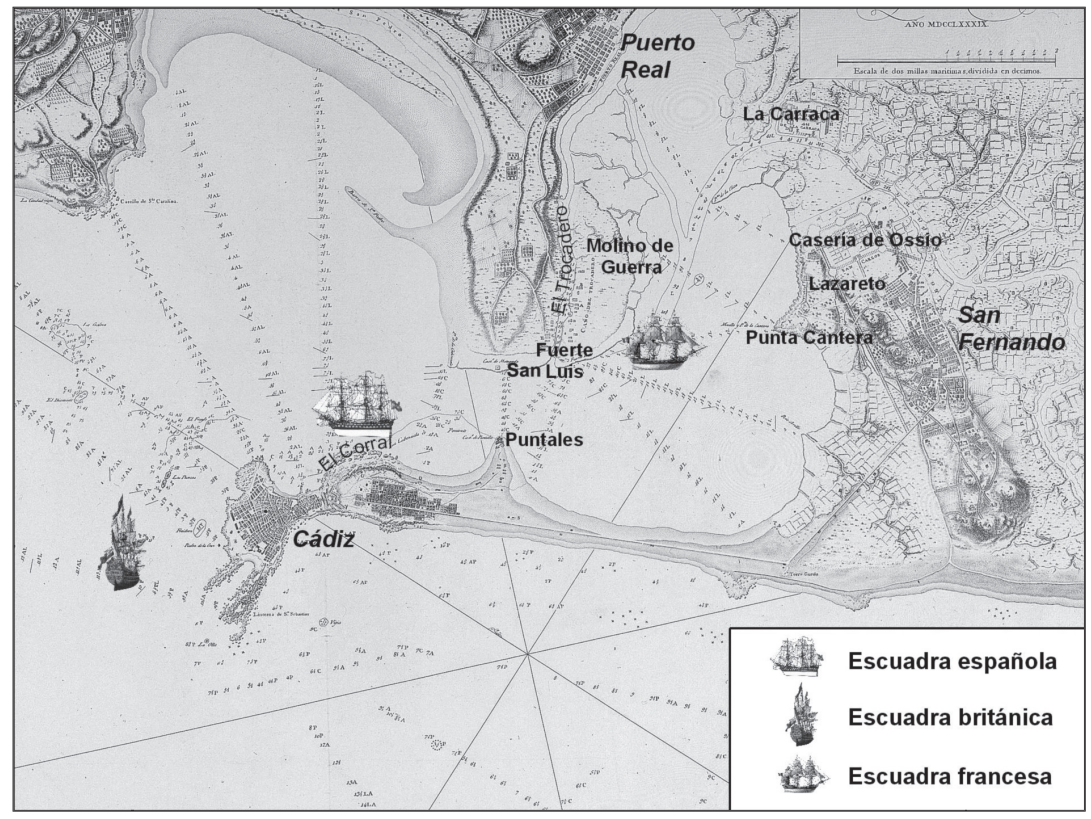

Fig. 4: Carta náutica de la Bahía de Cádiz. [Vicente Tofiño. 1789].

25 CLAVIJO CLAVIJO, Salvador: La ciudad de San Fernando. ....op. cit....p. 379.

26 Pequeña embarcación que se construye para llevar un mortero, cañón u obús montado, y batir más de cerca al enemigo.

27 PÉREZ DE SEVILLA Y AYALA, Vicente: La artillería española. ...op. cit., p. 203. 
Cádiz tenía ya experiencia en la utilización de este cuerpo de fuerzas sutiles para la defensa de la Bahía, ya que en el ataque inglés efectuado en 1797 por los almirantes ingleses Jervis y Nelson, Cádiz fue defendida por un cuerpo de 167 unidades de fuerza sutil a las órdenes de Mazarredo. Hecho histórico que quedó incluso reflejado en una letrilla popular:

\section{De que sirve a los ingleses tener fragatas ligeras, si saben que Mazarredo tiene lanchas cañoneras $^{28}$.}

El día 9 de junio de 1808, una vez finalizados todos los preparativos del plan de ataque, el capitán general Morla solicita del vicealmirante la rendición de su escuadra. Ante su negativa, éste ordenó desde la Torre Tavira mediante las señales del telégrafo óptico, al general Apodaca, a bordo del Príncipe de Asturias y a la Torre Alta en San Fernando (para que las repitiera y transmitiera al Arsenal) el ataque conjunto de las baterías de costa y las lanchas cañoneras que avanzaron desde el Fuerte de San Luis. Por lo que según fuentes españolas a las 3 11/4 horas de la tarde se rompió el fuego.

El general Moreno, jefe del arsenal de La Carraca, coordinó el ataque desde una falúa situada en el caño de la Carraca, mientras que el general Apodaca lo hacía a bordo de su buque insignia, el Príncipe de Asturias. La respuesta de Rosily fue según las memorias del capitán Sevilla, presente en dichas acciones: la escuadra francesa contestó al primer ultimátum con el ronco bramar de mil cañones ${ }^{29}$.

A las 2 1/4, horas (según las fuentes españolas a las 3 11/4 horas) del día 9 de junio de 1808 con viento de Oeste, relata el timonel Maffiotte que el fuego comenzó desde una batería de morteros ${ }^{30}$ establecida en la costa del norte del canal del Trocadero, el polvorín de Punta Cantera, el Arsenal de La Carraca y 25 cañoneras:

...El 9 Junio 1808 estando fondeado en el fondo de la bahía ha venido a mediodía un bote español a bordo del Buque Insignia y [ileg.] es [ileg.] 1/2 hora después el Almirante ha señalado de inmediato zafarrancho de combate, la Armada ha puesto las [ileg.] sobre la filástica aparejando los juanetes de sobremesana e izados los pabellones a popa...

El combate comenzó y nuestro timonel sigue relatando como el cuerpo de fuerzas sutiles, formado por las lanchas cañoneras españolas, inició el ataque avanzando desde el Fuerte de San Luis hacia la escuadra de Rosily:

...Nos han hecho fuego. Cada navio se ha batido con quien tenía más cerca. Las cañoneras españolas han levado sus anclas y se nos aproximaron a remo combatiendo constantemente, pero habiendo hecho abandonar las baterías del polvorín ${ }^{31}$ y del Trocadero su fuego ha disminuido y nosotros hemos contado 16 cañoneras que han retrocedido y fondeado en su primera posición desde donde ellas nos han disparado bombas hasta la medianoche pero nuestro fuego y el de otras baterías cesaron desde las ocho horas...

Maffiotte da cuenta de los daños del primer día del enfrentamiento:

...En esta jornada cayó una bomba en el castillo de proa que explotó en la batería de cañones del calibre 24 impactando en el cascabel ${ }^{32}$ de un cañón, dejando 16 ó 17 hombres fuera de combate...

\footnotetext{
28 MÁRTINEZ-VALVERDE, Carlos: "Sobre las fuerzas navales españolas en los siglos XVIII y XIX". Revista de Historia Naval, n 0 36, año X. 1992, p.38.

29 PÉREZ DE SEVILLA Y AYALA, Vicente: La artillería española. ...op. cit., p. 223.

30 Pieza de artillería, de gran calibre y corta longitud, destinada a lanzar bombas.

31 Probablemente se refiere al Polvorín de Punta Cantera, situado en la costa norte de San Fernando.

32 Remate posterior, en forma casi esférica, de algunos cañones de artillería.
} 
Cuenta además como el Neptune, navío donde se encontraba embarcado, recibió algunas balas en la arboladura:

...El día 10 de junio: a las 8 horas comenzó el fuego por las bombardas españolas fondeadas en la misma situación que en la víspera y la batería del Trocadero también volvió a iniciar el fuego. Una bomba cayó sobre una tronera de estribor y la ha destrozado en parte, a las 9 h. el polvorín comenzó su fuego y la Carraca a las 9 h. 1/4. El buque insignia nos dio a la voz orden de no hacer fuego sobre las cañoneras excepto que el hiciera la señal y la misma orden concerniente al Algeciras a quien nosotros la habíamos transmitido. El buque insignia, el Plutón, y el Vencedor hicieron fuego sobre la batería, el polvorín, la Carraca y el Trocadero Hacia el mediodía el buque insignia cesó el fuego. A mediodía 1/2 el Heros de nuevo comenzó a disparar. El viento era del OSO. A mediodía y $3 / 4$ algunas cañoneras han retrocedido Por aumentar el viento. A las 2 1/2 el almirante español pidió parlamentar. Se llegó a un acuerdo. El fuego cesó de ambos lados y estuvimos ocupados en reparar las averías, nada de nuevo hasta el día siguiente 11, a las $7 \mathrm{~h} . .$.

Sin duda, el cese momentáneo de las hostilidades convenía al vicealmirante Rosily, que pretendía ganar tiempo para contar con el apoyo de los refuerzos del general Dupont que se dirigía hacia el sur. Aunque no se imaginaba que estas tropas imperiales verían frenadas su avance hacia Cádiz en la derrota que les infligió el general Castaños, el día 19 de julio en la famosa Batalla de Bailén.

Los días 11, 12 y 13 de junio se produjo el movimiento de las lanchas cañoneras que fueron tomando distintas posiciones.

Maffiotte sigue relatando en sus memorias como:

...A las 6 el almirante español solicitó nuevamente parlamentar. Acordado. Nosotros nos dimos cuenta que el enemigo colocaba una cadena flotante desde el Fuerte de San Luis hacia el Sur. El día 13 mucho movimiento en el enemigo que levantaban baterías por todas partes. Nada más que destacar hasta el 14 por la mañana.

Finalmente el día 14, Rosily entrega su escuadra al ver que no tenía escapatoria ninguna y que seguir combatiendo significaba un terrible final. A las 6 de la mañana del día 14 de junio el Gobernador dio un ultimátum ofreciendo, a cambio de la rendición, la vida del vicealmirante y de las tripulaciones de los navíos franceses. Éste se rindió sin condiciones, haciendo entrega de su espada al general Apodaca, que le fue devuelta galantemente, pero quedó como prisionero de guerra.

Michel describió el final del conflicto armado, conocido como la Batalla de la Poza de Santa Isabel, de la siguiente manera:

...El 14 a las 5 horas de la mañana el almirante español decidió parlamentar. Se acuerda. A las 5 1/2 31 cañoneras y bombardas estuvieron tomando las posiciones que habian tenido los dos primeros días. El buque insignia señaló zafarrancho de combate a las 6 1/2. El almirante llamó a los comandantes de los navios que habían partido de su borda a las 7 horas. $Y$ han comunicado a sus tripulaciones que el almirante fue forzado a rendir sus navios al enemigo visto su gran superioridad. A las 8 h el buque insignia ha señalado imitar la maniobra y ha arriado su pabellón. A las 9 1/4 desembarcaron los destacamentos de los navios, fueron trasladados a bordo de diferentes pontones y la marinería a la prisión del Arsenal...

El balance de la victoria española fue de 12 muertos y 51 heridos en el bando francés y de 5 muertos y 50 heridos en el lado español; la captura de 5 navíos de línea y 1 fragata, 442 cañones, 1.651 quintales de pólvora, 1.429 fusiles, 1.069 bayonetas, 80 esmeriles, 50 carabinas, 505 pistolas, 1.696 sables, 425 chuzos, 101.568 balas de fusil, víveres para cuatro meses y 3.776 prisioneros de guerra ${ }^{33}$.

33 PÉREZ DE SEVILLA Y AYALA, Vicente: La artillería española. ...op. cit., p. 225. 
En reconocimiento a los servicios prestados la Junta de Sevilla premió con los grados intermedios a todos los oficiales de Marina y del Real Cuerpo de Artillería, que habían tomado parte en la acción.

Una vez finalizada la contienda, el comandante general Ruiz de Apodaca se hizo cargo de los buques rendidos, nombrando comandantes de los navíos franceses a los segundos comandantes de los navíos españoles y tomando como presos a las tripulaciones de todos los buques.

Los prisioneros de marinería y tropa fueron recluidos en La Carraca y a bordo de los navíos españoles Terrible y San Leandro, hasta que fueron conscientes las autoridades hispanas del peligro de insurrección si permanecían en estos buques. Por ello, se ordenó el traslado a los navíos desarmados Castilla y Argonauta, que como pontones prisión fueron amarrados a los muertos ${ }^{34}$ existentes en la bahía. Mientras que los oficiales, plana mayor y el almirante Rosily pudieron permanecer a bordo de sus respectivos navíos ${ }^{35}$.

Las condiciones en que fueron encerrados los prisioneros franceses fueron lamentables. Para la mayor parte de ellos el destino fue bastante duro, debido al hacinamiento provocado por el alto número de prisioneros que llegaron a concentrarse en la Bahía de Cádiz. Ya que a los 3.676 marinos de Rosily, pronto se les unirían los 17.350 hombres del general Dupont capturados en la Batalla de Bailén. Repartidos entre la prisión de San Carlos y 8 pontones al ancla en la rada gaditana, estos prisioneros vivirán un trágico encarcelamiento por las condiciones tan extremas que tuvieron que padecer.

La situación comenzaba a hacerse insostenible y la posibilidad de que surgiese una insurrección por parte de los prisioneros franceses, hizo que la Junta de Regencia se plantease disminuir el número de prisioneros en Cádiz. De modo que en 1809 los españoles envían 1.000 hombres a Inglaterra, 1.500 a Canarias y 5.300 a las Baleares. De estos últimos, 4.500 fueron abandonados en la desértica isla de Cabrera donde debido a la escasez de alimentos practicaron incluso hasta el canibalismo.

El balance total de la Guerra de la Independencia para Francia fue muy duro ya que de los 24.776 prisioneros militares y civiles de Cádiz, sobrevivieron solamente 7.082, es decir tuvieron una tasa de mortalidad de $70 \%{ }^{36}$.

Maffiotte fue hecho prisionero y conducido a una prisión pontón: ...el 25 llevado a bordo del pontón en la Carraca y el 12 de agosto fui transferido al barrio de San Carlos, cerca de la Isla de León...

Considerando peligrosa la estancia de tantos franceses en la Bahía de Cádiz, se decidió que 800 prisioneros fueran trasladados a las Islas Canarias en los navíos Fulgencio y San Lorenzo, a su paso para la Habana ${ }^{37}$. Es necesario decir que Maffiotte fue un prisionero con fortuna, ya que entre los marinos franceses embarcados para Canarias estaba nuestro timonel Michel. Lo relata de la siguiente manera:

...Salí del barrio de San Carlos el 25 de abril de 1809. Embarcado el mismo día a bordo del navío San Lorenzo, partí de Cádiz. El 12 de mayo llegué a San Cruz. El 11 desembarqué en Candelaria. El 2 de junio partí de Candelaria para Santa Cruz haciendo la ruta por tierra.

Finalmente, una vez establecida la paz con Francia, Maffiotte permanecerá en Tenerife, reorganizando su vida al participar en las actividades mercantiles de la ciudad, trabajó para un consignatario naviero debido a sus conocimientos de los idiomas francés, español e inglés. Posteriormente creó la Escuela de Náutica de Santa Cruz de Tenerife, siendo su director desde el año 1835 hasta su jubilación en 1864 y en la cual se encontraba el retrato que aportamos ${ }^{38}$ de un ya maduro Michel Maffiotte, que es una de las pocas fotografías que se conservan de un participante en el Combate Naval de Trafalgar y en la Batalla de la Poza de Santa Isabel ${ }^{39}$. Actualmente sus descendientes siguen residiendo en la isla de Tenerife.

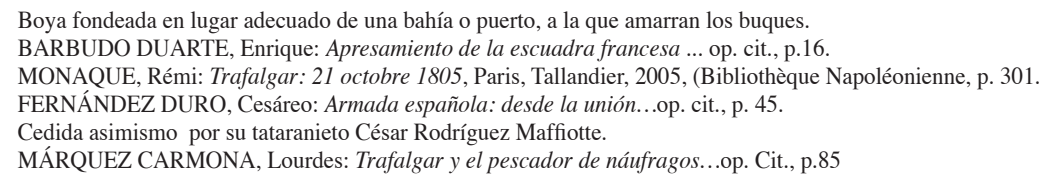


Finalizaremos mencionando que además de en los libros de historia, la rendición de la escuadra de Rosily quedó reflejada en una letrilla del cancionero popular gaditano ${ }^{40}$ :

\author{
En Cádiz una escuadra \\ la vimos entregar \\ a Morla y Apodaca, \\ rendida en tierra y mar. \\ Rosily, que era el jefe, \\ le llena de pesar \\ ver sobre su bandera \\ la nuestra tremolar. \\ $* *$ \\ Con las bombas que tira \\ el mariscal Soult \\ hacen las gaditanas \\ blondas de tul.
}

40 GELla ITURRIAGA, José: Estudios de la Independencia, Tomo II, 1966. En: Cancionero de la Guerra de la Independencia (http://www.1808-1814.org/poesia/cancion.html http://www.1808-1814.org/poesia/cancion.html) Consultado el: 21-10-2008. 